\title{
PODER AÉREO Y CONCURRENCIA REGULADA: \\ LAS RAÍCES DE LA POLÍTICA AÉREA ARGENTINA, 1935-1966
}

\author{
Melina Piglia \\ Consejo Nacional de Investigaciones Científicas y Técnicas, Universidad \\ Nacional de Mar del Plata (CEHIS, INHUS), Argentina \\ pigliamelina@gmail.com
}

\section{RESUMEN}

El presente artículo analiza los orígenes de la primera política aerocomercial integral en la Argentina entre 1935 y 1966. En específico, estudia la emergencia una mirada estatal nueva sobre los transportes modernos y su función pública, que cristalizó en la política aérea impulsada por el gobierno de facto (1943-1946). Las raíces de esta política se anclaban tanto en concepciones castrenses, alimentadas por el clima de previo a la Segunda Guerra Mundial, como en una serie de ideas discutidas por militares y civiles que encarnaron, durante la década de 1930, en el Estado. Esto ocurrió en un período de creciente intervención estatal en la economía y la sociedad que caracterizó esos ańos en la Argentina. Igualmente, se muestra que las líneas generales que emergieron de la normativa planteada en 1945 se convirtieron los principios en los que se apoyó la política aérea argentina posterior.

Palabras clave: Política aérea, Poder aéreo, Soberanía, Empresas públicas, Argentina. 
AIR POWER AND REGULATED CONCURRENCE:

THE ROOTS OF AVIATION POLICY IN ARGENTINA, 1935-1966

\section{ABSTRACT}

This paper analyzes the origins of Argentina's first integral commercial aviation policy between 1935 and 1966. Specifically, it examines the emergence of a new state approach to modern means of transport and their public function, which crystallized in the aviation policy implemented by the de facto government (1943-1946). This policy had its roots in both military concepts, fuelled by the climate prior to World War II, and a series of ideas debated by both the military and civilians which, in the 1930s, they embodied in the state. This occurred during a period in Argentina marked by growing state intervention in the economy and society. In addition, the paper shows that the main guidelines which emerged from the regulation proposed in 1945 became the principles that underpinned Argentina's subsequent aviation policy.

Keywords: Aviation policy, Air power, Sovereignty, State companies, Argentina. 


\section{INTRODUCCIÓN}

El desarrollo de la aviación comercial, como el de otros transportes modernos, ha transformado de modo profundo el mundo en que vivimos. Para los estados, la nueva actividad planteó toda una serie de desafíos y de posibilidades, a la par que el propio cielo debió ser construido como territorio de soberanía.

El presente artículo analiza los orígenes de la primera política aerocomercial integral en la Argentina y la perduración de sus líneas centrales. En Latinoamérica en general, y en la Argentina en particular, la cuestión del transporte aéreo ha recibido una atención académica escasa. La mayoría de las historias existentes sobre la aviación comercial proceden de fuera de los círculos académicos (e.g. Martínez 2013, Potenze 1987) En los últimos años, con la creciente influencia del llamado mobility turn (Urry y Sheller 2006) la aviación comercial ha sido objeto de nuevas indagaciones desde una perspectiva que busca poner de relevancia el modo en que las movilidades aéreas (y sus espacios, redes, sujetos, sistemas) son producidos y reproducidos, funcionan y son regulados, atendiendo a sus consecuencias sobre la vida social y a sus relaciones con otros sistemas de movilidad (Piglia 2017: 33). Algunos aspectos han de la política área, pensada desde esta perspectiva, han sido analizados por Anahí Ballent, que ha estudiado la compleja operación territorial involucrada en la construcción del aeropuerto de Ezeiza en la segunda mitad de los ańos cuarenta (Ballent 2002); otros aspectos, han sido el foco de los trabajos de Melina Piglia sobre Aeroposta y sobre la política aérea y la modernización técnica durante los años cincuenta y sesenta (Piglia 2016, en prensa).

Argentina había sido hasta la Segunda Guerra Mundial la economía más dinámica, más industrializada y moderna de Sudamérica y todavía aspiraba a liderar la región. Pese a su lugar más bien periférico, había sido uno de los primeros países del continente en disponer de una línea área de base local y sería el primero en utilizar aviones a reacción. El caso argentino, en el que el desarrollo de la aviación formó parte de un proyecto nacionalista, resulta especialmente interesante.

El artículo analiza la emergencia una mirada estatal nueva sobre los transportes modernos y su función pública en la Argentina, que cristalizó en la política aérea impulsada por el gobierno de facto (19431946). Sostendremos que las raíces de esta política se anclaban tanto en concepciones castrenses, alimentadas por el clima de preguerra, como en una serie de ideas discutidas por militares y civiles que encarnaron, avanzados los años treinta, en el Estado, en diálogo además con el proceso de 
creciente intervención estatal en la economía y la sociedad que caracterizó esos años en la Argentina. Plantearemos, además, que las líneas generales de la política aérea planteada en 1945 tendrían una extensa perduración.

Consideramos que el análisis de estas cuestiones resulta central no solo comprender más cabalmente la política aérea y el desarrollo de la aviación comercial en este rincón de América, y sino que contribuye también a iluminar los debates en torno a los procesos de modernización de los estados latinoamericanos.

\section{PRIMEROS PASOS}

Desde 1919 la incipiente aviación civil argentina estaba oficialmente bajo la autoridad del Ejército y del Ministerio de Guerra, a cargo del recién creado Servicio Aeronáutico del Ejército, y más tarde del Departamento de Aeronáutica dentro del Ministerio de Guerra. Sin embargo, a la vez, otras instituciones dentro y fuera del Estado también tenían injerencia sobre la aviación civil. Como parte de las Conferencias de Paz, en octubre de 1919, 19 países habían firmado en París la Convención para la Reglamentación de la Navegación Aérea Internacional, que reconocía expresamente la soberanía de los estados sobre el espacio aéreo, admitiendo a la vez el derecho de sobrevuelo inofensivo de aeronaves extranjeras ${ }^{1}$. Aunque la Argentina no ratificó el convenio hasta 1935, sus normas funcionaron como marco orientador. En 1925 la Federación Internacional de Federaciones Aeronáuticas reconoció al Aeroclub Argentino y a la Dirección de Correos y Telégrafos como autoridades de aplicación de la Convención de París en la aeronáutica civil argentina, papel en el que fueron confirmados por el propio Estado nacional. Unos años más tarde, el gobierno solicitó al Aeroclub la preparación de un anteproyecto de ley de aeronavegación civil, que sería discutido en las Primera Conferencia de Aeronáutica Civil (1933) y luego (sin éxito) en el Congreso Nacional. El gobierno de Alvear (1922-1928) elaboró en 1925 un Reglamento para la aeronavegación, siguiendo las normas de la Convención de París, pero le sumó algunas disposiciones de seguridad territorial militar, sugeridas por

1 Muchos países protestaron contra los artículos que establecían privilegios excesivos para los países que habían ganado la guerra; estos fueron modificados en sucesivas convenciones en 1926 y 1929 (HCDN. Sesiones del 29 y 30 de julio de 1934: 724725).

2 Se realizaron nueve Conferencias entre 1933 y 1942 y se creó un influyente Comité Argentino Permanente de Aeronáutica. 
los ministerios de Guerra y Marina ${ }^{3}$. Estas disposiciones, inspiradas en una concepción de nacionalismo y defensa nacional muy atada a una visión demasiado limitada de la integridad territorial, resultaban irritantes para los países limítrofes e implicaban obstáculos para los vuelos internacionales que comenzaban a organizarse por entonces ${ }^{4}$. Denunciadas en sucesivas conferencias internacionales, serían finalmente abandonadas por completo en 1932.

En 1929 comenzó a volar la primera línea aérea regular radicada en el país, Aeroposta Argentina, con servicios a Asunción, a Santiago de Chile y, desde 1930, a Comodoro Rivadavia y luego Río Gallegos desde Bahía Blanca. Aeroposta tenía un convenio para la distribución de correo y, como servía los yacimientos de petróleo de la costa patagónica, recibía también contribuciones en combustible de Yacimientos Petrolíferos Fis

cales (YPF) $)^{5}$. En 1929 comenzaron a operar también dos empresas norteamericanas, Nyrba (New York Río and Buenos Aires Line) y Panagra (Pan American Grace Airways). Se trataba de líneas internacionales, pero explotaban, secundariamente, líneas de cabotaje. La depresión económica internacional que había comenzado en 1930 agudizó el déficit operativo de las líneas aéreas característico de la actividad en todo el mundo en esta etapa. En 1930 Nyrba fue absorbida por Panam (a su vez vinculada a Panagra). Los vuelos de Aroposta debieron ser suspendidos en 1931 por falta de financiamiento, mientras en Francia la empresa matriz entraba en liquidación judicial.

A fines de 1931 el gobierno argentino de facto ${ }^{6}$ tomó a su cargo los

3 Los hidroaviones y anfibios debían matricularse inicialmente ante el Servicio Aeronáutico Naval y los aviones, dirigibles y globos, ante el Servicio Aeronáutico del Ejército. Luego de 1927, el gobierno crearía la Dirección General de Aeronáutica con la categoría de Gran Repartición y, dentro de ella, la Dirección General de Aeronáutica Civil, en la que recayó el control de las aerolíneas comerciales.

4 Así, por ejemplo, el mero sobrevuelo en aeronaves tripuladas por miembros militares o civiles de un gobierno extranjero requería de un permiso especial tramitado por la vía diplomática y, si se trataba de vuelos sin esa condición, de una serie de permisos ante el Ministerio de Guerra o el de Marina.

5 La conexión aérea que ofrecía Aeroposta resultaba fundamental para las operaciones de los yacimientos petroleros de YPF cercanos a Comodoro Rivadavia, una zona que no tenía conexión por ferrocarril y a la que se demoraba más de una semana en llegar por vía marítima.

6 En septiembre de 1930 se produjo el primer golpe de estado de una larga serie en 
servicios, alquilando a la Aeroposta todos sus bienes y financiando el déficit operativo a medias entre la Dirección de Aviación Civil y el Correo. De las rutas de Aeroposta, el Estado solo mantuvo funcionando la ruta patagónica, de forma parcial: una frecuencia semanal Bahía BlancaComodoro Rivadavia y otra Bahía Blanca-Río Gallegos. La explotación directa de Aeroposta obedeció en parte a la presión de los propios pobladores (y de los concentrados intereses comerciales) de la Patagonia; respondía, como otras intervenciones del Gobierno Provisional y luego del gobierno constitucional -pero fraudulento- del general Agustín P. Justo, a un diagnóstico en clave territorial de los problemas argentinos, para el que la falta de integración del territorio y el desarrollo desigual del Litoral y el interior del país eran la clave de los males argentinos (Ballent y Gorelik 2002).

En mayo de 1932 le fueron devueltos a la Aeroposta Argentina SA todos sus bienes. La administración de Justo continuó con el apoyo a Aeroposta, que quedó reducida a su línea en la Patagonia, pero prefirió una opción más económica: un subsidio fijo anual ${ }^{7}$. Los problemas financieros de la empresa, sin embargo, continuaron. Y derivaron en 1936 en la venta de la casi totalidad del paquete accionario de la filial argentina a un grupo de accionistas argentinos. El nuevo grupo consiguió del gobierno de Justo una mejora sustantiva en el subsidio, que pasó a cobrarse, además, sobre la base de los kilómetros volados (Piglia 2016).

\section{LOS AÑOS TREINTA Y LOS PROYECTOS PARA CENTRALIZAR LA POLÍTICA AÉREA}

A principios de 1935 la ley 12152 aprobó la adhesión de la Argentina a la Convención de París (B.O.R.A. 7 de mayo de 1935: 188). Promulgada la ley, a la Dirección de Aeronáutica Civil (DAC) se le encomendó el estudio y elaboración de un plan para una red nacional de rutas aéreas internas, que debían ser puestas a remate público. En su informe, la DAC proponía un sistema de cinco rutas troncales estructurado en torno a Tucumán y Buenos Aires como nodos principales y Bahía Blanca y Corrientes como nodos secundarios (véase Mapa 1). La primera de esas rutas, se superponía

Argentina. El general José Félix Uriburu ocupó la presidencia de facto hasta febrero de 1932.

7 Entre 1931 y 1933 el subsidio fue de $\$ 10.000$ y $\$ 20.000$ y se hizo efectivo a través de la entrega de combustible de la petrolera estatal (YPF); entre 1934 y 1936, el subsidio dejó de depender de YPF y se multiplicó por nueve llegando a los \$180.000 anuales. 
al Ferrocarril Pacífico y Trasandino, conectando Buenos Aires con Mendoza (con escalas intermedias) y de ahí con Santiago de Chile y Valparaíso, y era operada por entonces por Panagra (DAC 1935: 1). La segunda, la ruta costera patagónica estaba en funcionamiento operada por Aeroposta, pero solo entre Buenos Aires y Río Gallegos; la DAC proponía una extensión a Buenos Aires (evitando la conexión por ferrocarril) y otra a Río Grande vía Magallanes (Chile) (DAC 1935: 2-3). La DAC sugería el establecimiento de otras tres rutas. La primera debía ser la del Litoral, partiendo de Buenos Aires y siguiendo al comienzo el trazado del río Uruguay (con escalas en Entre Ríos) y luego los ríos Paraná y Paraguay, con escalas en ciudades de Corrientes y Formosa y Asunción del Paraguay. La ruta podía luego expandirse de modo transversal, conectando Concordia y Paraná, Corrientes, Posadas y Puerto Aguirre (luego Puerto Iguazú) y Corrientes y Tucumán, vía Chaco. La ruta N.o 4, la segunda que debía ser establecida, uniría Buenos Aires con Salta, con escalas en Rosario, Córdoba, Santiago del Estero y Tucumán, donde a partir de rutas secundarias, articulaba con la línea N. 3 al Litoral y la línea N.o 1 a Mendoza y Chile. Se trataba de una línea que competía con el ferrocarril y que, por ello, se anticipaba mucho menos rentable que la del Litoral, pero a la vez se la consideraba el "núcleo neurálgico" de todo el sistema: la regularidad y puntualidad -que, sostenían, aficionaría al público al servicio aéreo- y el apoyo de las provincias serían necesarios para su mantenimiento. Esta ruta troncal enlazaría con rutas secundarias: la ya mencionada Tucumán-ChacoCorrientes, una entre Tucumán y Mendoza y otra Villa María-Río Cuarto (Córdoba)-Villa Mercedes (San Luis) que conectaría esa línea con la ruta No1. Finalmente, se proponía una ruta cordillerana, la del Parque Nacional del Sud, que unía Bahía Blanca, Neuquén, Bariloche y Esquel.

El informe de la DAC era una seńal de la emergencia de un proyecto para establecer un sistema nacional de rutas aéreas que, como había sucedido con la construcción de la red nacional de caminos a partir de 1932, desempeñaría funciones de fomento del desarrollo y de la integración nacional. Este proyecto, y una demanda más profunda de establecer una política nacional rectora en materia de aviación, formaba parte central de las demandas de un emergente núcleo de "intereses aeronáuticos", congregados por ejemplo en torno a las conferencias nacionales de aviación, que desde 1933 reunían a aviadores civiles y militares y a representantes de los aeroclubes, de las empresas aéreas, de la DAC, de los Correos y Telégrafos y de YPF. En las conferencias y en el Comité Argentino Permanente de Aeronáutica (usina local de propuestas de regulación en materia aeronáutica) los aviadores militares tenían una gravitación fundamental ${ }^{8}$.

8 En el Comité Argentino Permanente de Aeronáutica, participaban personajes como 
Sin embargo, a la hora de elaborar los pliegos de condiciones para el remate de líneas aéreas, la DAC se encontró con dificultades que derivaban de la ausencia de una línea estatal clara en materia de transporte aéreo y en medio de las presiones de las empresas en funcionamiento, como Aeroposta, por ejemplo, cuyos directivos tenían buenos contactos con el gobierno y aspiraban a quedarse con las rutas proyectadas al Litoral, a la Patagonia cordillerana y a Punta Arenas (Chile) (Aeroposta 1939a: 18-20). ¿Debía permitirse a los capitales extranjeros explotar el cabotaje o favorecerse a los nacionales -como Aeroposta? ¿Era deseable que distintas compañías compitieran entre sí en la explotación de la misma ruta aérea? ¿Hasta qué punto y cómo debía el Estado apoyar financieramente a las empresas y controlarlas? ¿Cómo garantizar que se cumpliera el rol del fomento del progreso que el Estado le adjudicaba, crecientemente, al transporte aéreo?

En junio de 1937, el Poder Ejecutivo encomendó a Eduardo J. Bullrich, un informe sobre la cuestión del transporte aéreo que permitiera fijar la política más conveniente para la Nación. Bullrich era abogado, había sido subsecretario del Interior durante el gobierno de Uriburu y había formado parte de la Comisión que elaboró en 1932 el nuevo marco legal e institucional que convirtió a YPF en reguladora del mercado de las naftas (Gadano 2006: 370-371, 398); entre 1934 y 1936 había sido secretario privado de Justo y desde 1936 presidía el tribunal arbitral que regulaba los conflictos entre YPF y las petroleras privadas. Justo consideraba que como la cuestión de la política aérea estaba íntimamente ligada a "múltiples intereses políticos y económicos, y entre ellos y de no menor importancia, al de la defensa nacional", Bullrich podría brindar una "opinión independiente, de orden general, por encima de los intereses creados" y por ello lo disuadió de nombrar una comisión técnica, en la que esos intereses se harían presentes con mayor peso (Bullrich 1938: 10).

Bullrich demoró más de un año en elaborar su informe, luego de largas consultas con reparticiones públicas, fuerzas armadas organizaciones civiles como el ya mencionado Comité Argentino Permanente de Aeronáutica. En el extenso trabajo, presentado en octubre del ańo siguiente y que se coronaba con un proyecto de ley, concluía que para el desarrollo real del transporte aéreo en la Argentina, clave para el progreso del país, resultaba fundamental fijar, a través de una ley orgánica nacional, una política nacional en materia de transporte aéreo que fuera más allá del mero ejercicio

el ingeniero Francisco de Artega, ligado a la fundación de la Fábrica Militar de Aviones y que sería luego Director de Aviación Civil (1939-1941), Marcos A. Zar, jefe y fundador de la aviación naval y el Coronel Parodi, Comandante de Aviación del Ejército a finales de los años treinta (Aeroposta 1939b: 39). 
del poder de policía del Estado y subordinara la actividad a las "necesidades económicas, políticas y administrativas del Estado", evitando además las políticas provinciales inconexas (el modelo era probablemente aquí el de la muy eficiente Dirección Nacional de Vialidad) (Bullrich 1938: 14). El Estado debía regular y controlar las rutas y los servicios, el material de vuelo, el tránsito aéreo, las licencias, la formación y el entrenamiento del personal, la construcción, habilitación y uso de la infraestructura de tierra y las radiocomunicaciones (Bullrich 1938: 34-35).

Para Bullrich, la intervención del Estado en el transporte aerocomercial era un imperativo, en tanto existía un innegable "interés político del Estado" en la actividad. Este interés se debía a múltiples cuestiones:

[...] el fomento de determinadas regiones alejadas de comunicaciones fáciles, o que no tienen otra clase de enlace, al interés político general de asegurar un mejor sistema de comunicaciones y transportes de centros económicos que lo requieran, al interés político de efectuar ciertas funciones de gobierno en que la aviación civil y comercial actúa como auxiliar o elemento de acción insustituible (lucha contra plagas, aviación sanitaria, aerofotogrametría, transporte de correspondencia y encomiendas postales) y a fin de servir como medio de propaganda internacional (Bullrich 1938: 28).

La defensa nacional era otro de los grandes motivos, ya que la flota comercial podía convertirse en flota militar auxiliar durante una guerra ${ }^{9}$ y porque la aviación comercial permitía mantener una reserva de pilotos en permanente entrenamiento; también contribuía indirectamente a la defensa nacional, por el desarrollo de rutas aéreas, infraestructura, conocimientos geográficos e integración nacional que promovía (Bullrich 1938:29). Sin embargo, Bullrich afirmaba que, aunque la defensa nacional fuera en última instancia el más importante de los objetivos que orientarían la intervención estatal en esta materia, no era el único, y subrayaba el peso del "interés político general". Atendiendo a ese interés más amplio y para asegurar que se cumplieran las "condiciones particulares" que la aviación comercial demandaba para desarrollarse ("la seguridad, la regularidad y la eficiencia del servicio y en último lugar la velocidad del mismo", Bullrich 1938: 32), no resultaba conveniente, en su opinión, que la aviación comercial quedara bajo control exclusivo de las Fuerzas Armadas.

9 Bullrich señalaba que esto era cada vez más dificil, puesto que los cambios técnicos de las máquinas de guerra hacían cada vez más difícil la reconversión de aviones civiles en aviones de guerra (Bullrich 1938: 39). 
El informe analizaba separadamente los casos de las rutas internacionales y las domésticas. Respecto de las primeras, discutía lo que según refiere eran las posiciones imperantes hasta entonces en la DAC y que planteaban el objetivo de la autarquía aérea: "rodear a la República de una muralla china en materia de aviación y no dejar que penetrasen en su territorio [...] las líneas internacionales" (Bullrich 1938: 39). En su lugar, proponía regirse por el principio de reciprocidad, aplicando convenciones multilaterales o bilaterales para "ofrecer a la aviación argentina la posibilidad cercana o futura de extender su explotación a distancias que le ofrezcan un rendimiento comercial inmediatamente aprovechable" (Bullrich 1938: 43). Bullrich asumía que las rutas más largas resultarían más redituables y compensarían los déficits del cabotaje (Bullrich 1938: 42), algo que la experiencia de los primeros ańos de vuelos internacionales de empresas argentinas probaría erróneo ${ }^{10}$.

En materia de cabotaje, el informe sostenía enfáticamente que "el Estado argentino debe por todos los medios a su alcance, tratar de que la navegación comercial en los servicios internos sea desempeñada por empresas real y efectivamente argentinas, mixtas o privadas", único medio de garantizar que se preservaran los intereses nacionales (Bullrich 1938: 84). Como había sostenido en su momento respecto del mercado de las naftas, Bullrich estaba a favor de un mercado de concurrencia regulada: la experiencia mostraba que la libre competencia, aún en las muy favorables condiciones norteamericanas, por ejemplo, conducía a la ruina de las empresas y al establecimiento de compañías cuyo único objetivo era acceder a las ayudas estatales (subsidios directos o indirectos, créditos, etc.), en desmedro de un servicio eficaz (Bullrich 1938: 50). Descartaba asimismo el sistema de monopolio directo, porque sostenía que era riesgoso para el Estado y porque, afirmaba casi como un axioma, "la capacidad comercial y técnica del Estado es casi siempre deficiente en relación a la particular" (Bullrich 1938:51). Se mostraba más favorable, en cambio, a los sistemas intermedios "que aseguren, por un parte la capacidad de dirección técnica y comercial y el aporte financiero privado y la participación del Estado", por aporte de capital directo u ofreciendo "ventajas, riquezas, créditos, subvenciones o infraestructura" (Bullrich 1938:51). Las empresas mixtas, como la belga Société Anonyme Belge d'Exploitation de la Navigation Aérienne (SABENA), eran para Bullrich una de las formas más deseables para el caso argentino.

10 Los aviones a pistón con los que se realizaron los vuelos internacionales hasta 1959 resultaban muy poco rentables. La rentabilidad comenzó a mejorar recién cuando Aerolíneas adquirió Jets Comet IV (los primeros de Sudamérica) y mucho más tras su reemplazo por los Boeing 707 en 1966. 
Basándose en el informe de la DAC, proponía dividir al territorio en cinco grupos de servicios o líneas que se adjudicarían a tres o cuatro empresas diferentes: Norte (Noroeste), Litoral, Oeste (Buenos Aires-Cuyo y La Pampa) y dos líneas patagónicas, la Sur (que incluía la costa y ramales futuros a la cordillera austral) y la Cordillerana con núcleo en Neuquén (Bullrich 1938: 98) (véase Mapa 2). Bullrich sugería que las líneas Norte y Oeste o Norte y Cordillerana se adjudicaran a una sola empresa y las demás cada una a una firma diferente (las líneas sur costera ya estaba adjudicada a Aeroposta). Recomendaba también que en el primer período de concesión, que debía durar unos ocho años, un par de estas compañías fueran empresas mixtas ${ }^{11}$ (particularmente la que tomara la línea cordillerana): la experiencia sería una prueba para comprobar si el funcionamiento del sistema se adaptaba a nuestro medio y podría generalizarse más adelante. Las demás compañías serían totalmente privadas y contarían con subsidios estatales. Las aerolíneas serían coordinadas por un consejo administrativo de enlace, presidido por una persona nombrada por el Poder Ejecutivo pero integrado por las empresas, que permitiría la coordinación de los servicios (Bullrich 1938:100).

Bullrich tenía así en cuenta la ya clara tendencia mundial hacia una creciente unificación y concentración de las empresas (tanto en la aviación nacional como en la internacional), de modo "libre" en el caso de Estados Unidos, de modos regulados en casos como Alemania o Gran Bretaña. El sistema, afirmaba, permitía una explotación más eficiente de los servicios y ahorraba recursos estatales (Bullrich 1938: 60); sin embargo, a su juicio, en el caso argentino era prematura una excesiva concentración, dada la vastedad y variación de su geografía: proponía, en cambio, el monopolio por regiones (Bullrich 1938: 96).

11 Bullrich recomendaba que el Estado tuviera acciones de goce que le garantizaran el 60\% de los votos en las Asambleas, al estilo de SABENA, como contraprestación a aportes de infraestructura, créditos o subvenciones acordados (Bullrich 1938:104). 
Mapas 1 y 2: Rutas aéreas planificadas por la DAC en 1935 y rutas aéreas propuestas por Bullrich en 1938 (izquierda y derecha, respectivamente)
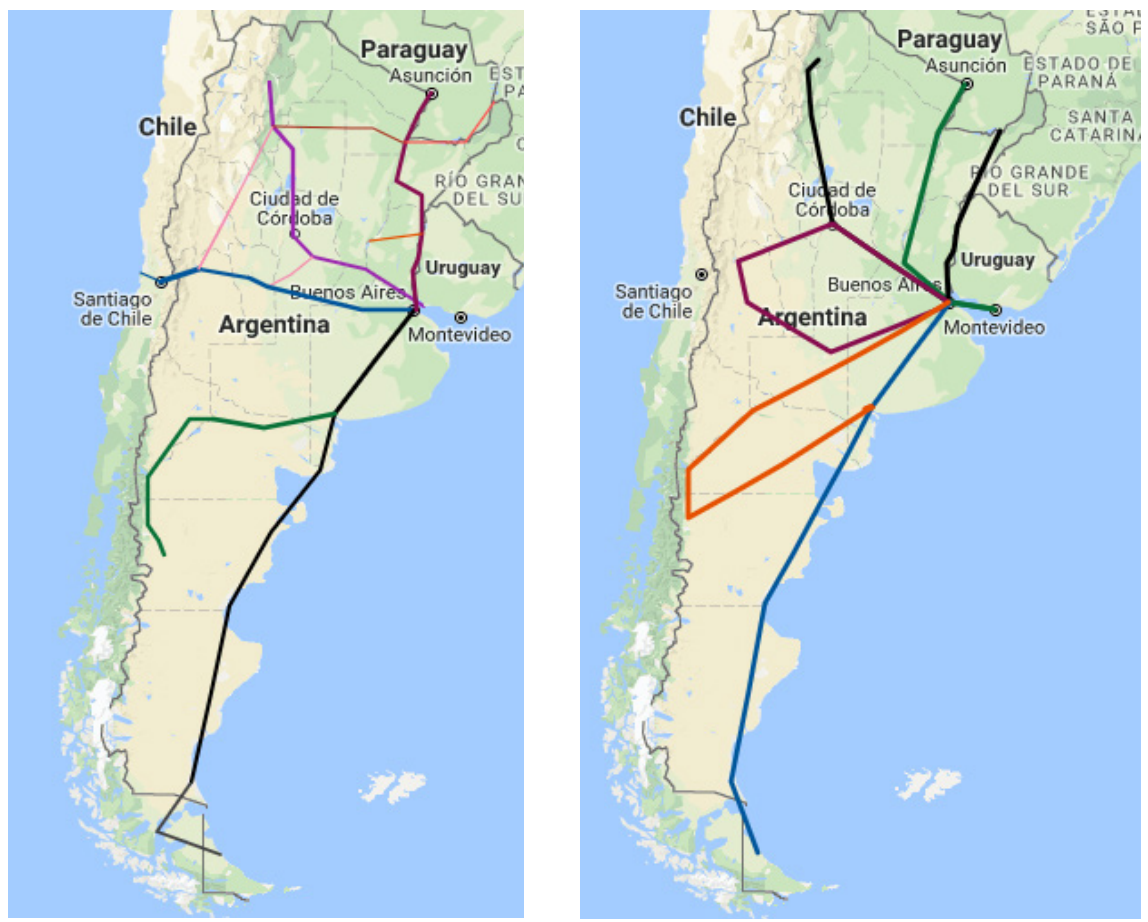

Nota: En el Mapa 1, las rutas troncales tienen un trazo más grueso; las rutas secundarias están en trazos delgados. En el Mapa 2 la ruta norte está en negro, la ruta oeste en rojo, la ruta cordillerana en naranja, la ruta litoral en verde, y la ruta sur en azul. Fuente: Elaboración propia sobre la base de DAC (1935) y Bullrich (1938: 97-98).

Su propuesta implicaba una mayor integración entre las rutas occidentales del país, que se articularían en los nodos de Córdoba y, quizás de Mendoza (ya que planteaba una posible futura extensión Neuquén-Mendoza), pero sobre todo en tanto pertenecerían a la misma empresa, mientras la conexión noreste-noroeste se debilitaba y Buenos Aires tenía aún más importancia, ya que era origen de todas las rutas (véase mapas 1 y 2 ).

Bullrich consideraba que las empresas que explotaran el cabotaje debían ser nacionales, al igual que la mayoría de sus accionistas. Esto apuntaba a prevenir formas de control y aprovechamiento extranjero y a permitir el desarrollo de la industria aeronáutica nacional (otro de los objetivos a los que se aspiraba y que, conjeturaba, sería probablemente boicoteado de forma activa por las empresas extranjeras de países productores de aeronaves 
que operaran en el país, Bullrich 1938: 88). El informe reconocía, sin embargo, la necesidad de introducir salvedades vinculadas a "la ausencia de compañías nacionales en la ruta o razones de interés general aconsejen su autorización” (Bullrich 1938: 44). Esas excepciones debían ser materia de tratados bilaterales, y Bullrich aconsejaba que estos se hicieran con países limítrofes y de un nivel de desarrollo aerocomercial similar, de modo de garantizar la reciprocidad: el esquema propuesto afectaba, por lo tanto, de manera directa las rutas que por entonces explotaba Panagra en el centro y norte del país.

El informe, presentado en octubre de 1938, se cerraba con un anteproyecto de ley orgánica de Aviación civil que corrió la misma suerte que otros antes que él (presentados por la Dirección de Aeronáutica Civil o por distintas fuerzas políticas) y no llegó a tratarse.

Tampoco se definió claramente una política aerocomercial, ni se fortaleció el papel de la Dirección de Aeronáutica civil ni se realizaron concursos para la adjudicación de nuevas rutas. La Corporación Sudamericana de Servicios Aéreos comenzó a operar en los años cuarenta una ruta, entre Montevideo, Buenos Aires y Asunción, con escalas sobre el río Paraná. Otras empresas, como Aeroposta y Panagra, ampliaron sus rutas, con lo que en buena parte las regiones delineadas por Bullrich tuvieron algún tipo de servicio, pero el marco siguió estando dominado por las medidas parciales.

\section{EL “PODER AÉREO” Y LAS LÍNEAS AÉREAS DEL ESTADO}

Desde los años treinta, los militares argentinos venían considerando a la aviación como un aspecto central de la defensa nacional, en una concepción que desbordaba la idea de la aviación militar. El concepto rector era aquí el del "poder aéreo nacional". Desarrollado por la aviación militar norteamericana, se definía como la aptitud total de una nación para volar: comprendía la actividad aérea total, tanto civil y como militar, comercial y privada, existente y potencial, las máquinas, la industria, los insumos, el personal entrenado, los combustibles e incluso una actitud pública favorable (la "conciencia aeronáutica") que alentara vocaciones aeronáuticas (Güiraldes y Rawson Bustamante 1949: 22-29).

Lograr entrenar (y mantener entrenado) un cuerpo suficientemente amplio de pilotos al que recurrir en caso de guerra, sin tener que afrontar los costos de una amplísima fuerza aérea, resultaba una preocupación recurrente en esos círculos en los años treinta y cuarenta. Estas preocupaciones estaban en sintonía con el clima de los años previos y del comienzo de la Segunda Guerra Mundial. La cuestión de los pilotos era 
una preocupación generalizada: en Gran Bretaña, por ejemplo, en los años previos a la Segunda Guerra (Adey 2010: 26-29), una serie de iniciativas oficiales y civiles -como la Air League que buscaba propiciar actividades aeronáuticas entre los Boy Scouts- buscaron despertar vocaciones y entrenar pilotos civiles y, en general, iniciar a la población en la cultura del aire con explícitos objetivos de defensa nacional. Más ampliamente, disponer de una población crecientemente aérea y de un cuerpo en expansión de pilotos civiles aparecía como una de las llaves para la modernización, como condición para las tareas de un estado moderno. Así, en 1944 YPF creó la Institución Aeronáutica YPF, que con recursos proveídos por la empresa, suscripciones de sus propios empleados y el apoyo de varios aeroclubes, entrenaba de modo gratuito a empleados estatales como pilotos civiles ${ }^{12}$.

En los primeros meses de su existencia se suscribieron 6500 empleados y se recibieron 300 solicitudes de postulantes a pilotos;

[La] elocuente respuesta del personal a la invitación formulada, fue la magnífica revelación del entusiasmo que despiertan las cosas del aire, demostrando que ya existe una conciencia aeronáutica formada $y$ un enorme potencial humano que solo requiere ser estimulado para que se incorpore a las actividades aéreas (Boletín de Informaciones Petroleras abril de 1945: 32).

En 1945 se graduaron los primeros de ellos, todos trabajadores de YPF, y la Institución afirmó su intención de extender esa formación gratuita a todos los empleados públicos que lo solicitaran (Boletín de Informaciones Petroleras abril de 1945:31-33).

La inminente conflagración mundial catalizó las preocupaciones por la defensa nacional. En ese contexto el Comando Aéreo del Ejército presentó al Ministerio de Guerra en 1939 un proyecto para la creación de una línea área de fomento: Líneas Aéreas del Sudoeste (LASO). LASO se ocuparía de la ruta de la cordillera, en la norpatagonia andina (prevista tanto en el diseño de la DAC como en el de Bullrich), realizando vuelos entre la base aérea de El Palomar (en las afueras de Buenos Aires) a las ciudades de Neuquén, Bariloche y Esquel, con escalas en otras ciudades menores.

De acuerdo con el proyecto, el objetivo principal era de orden militar: vincular entre sí a las bases del Ejército, muchas de ellas en zonas fronterizas y colaborar en el entrenamiento del personal del Comando Aéreo para

12 La formación de los pilotos civiles, que tenían que pagar cursos, entrenadores y horas de vuelo 
volar en las variadas condiciones de la Patagonia, profundizando además el conocimiento de esa zona "probable teatro de operaciones [...] en caso de conflicto armado" (Parodi 1939: 5). "Con la existencia de dicha línea aérea -sostenía el proyecto- la Aviación del Ejército hará efectivo su control sobre el cielo patrio de esa región" (Parodi 1939: 5).

En segundo lugar, las LASO desempeñarían una función de "fomento" del desarrollo y de la integración nacional, construyendo rutas aéreas allí donde -supuestamente- el capital privado no se interesaba en invertir, dado su escaso rendimiento, y sin necesidad de que el Estado proveyera las fuertes subvenciones que requeriría una línea comercial. La propuesta del Comando permitía ayudar a encarar el desarrollo del transporte aéreo en el país con el mínimo de erogaciones ${ }^{13}$, aprovechando los pilotos militares (cuyos sueldos estaban ya cubiertos por el Ejército) y los aviones disponibles (Parodi 1939: 7). La población civil se beneficiaría, al quedar ligada más rápidamente con la Capital Federal, ya que las comunicaciones en la región eran lentas y difíciles, pero también se fortalecería la afirmación de la soberanía en una zona que los militares veían con preocupación: "desde el punto de vista político-social, la vinculación rápida de dicha zona con la Capital Federal, le llevará el progreso y la desvinculará paulatinamente de Chile, contrarrestando la penetración pacífica realizada por ese país hasta hace poco" (Parodi 1939: 5). LASO comenzó a volar de forma experimental en diciembre de 1939; el servicio regular se estableció en septiembre de 1940 y transportó, hasta 1945, un promedio de alrededor de 1500 pasajeros al año (Datos estadísticos 1945: s/n) ${ }^{14}$.

Los planes eran extender más tarde la línea con rutas auxiliares al Lago Buenos Aires y al Lago Argentino, continuando así hasta el estrecho de Magallanes, un desarrollo previsto en el informe de Bullrich como posible extensión de la ruta del sur. Aeroposta que, como dijimos, había procurado sin éxito obtener la concesión de la ruta a Bariloche y Esquel, obtendría poco después la concesión de parte de esa extensión que LASO había planificado: la ruta Comodoro Rivadavia-Lago Buenos Aires-Cañada

13 El proyecto calculaba un producido anual para la línea de $\$ 346.424$, incluida la correspondencia, (el monto equivalía a cerca de un $20 \%$ de los ingresos de explotación de Aeroposta en esa época) Los gastos de personal, combustible y acondicionamiento de aeródromos (no demasiado oneroso por el tipo de aviones de que se trataba), derivarían del presupuesto de la Comando. Se usaría el material existente y los repuestos serían provistos por la Fábrica Militar de Aviones.

14 Aeroposta transportó 3.300 pasajeros en 1940 y 7.300 en 1945. 
León-Lago Argentino-Río Gallegos ${ }^{15}$. No obtuvieron, sin embargo, como deseaban, la extensión de ese servicio hasta Punta Arenas (que era lo que en realidad podría haber implicado un negocio más interesante, sobre todo en materia de correspondencia).

Tras la experiencia exitosa de LASO, el Comando resolvió la creación de una línea al Litoral. Tenía un trazado más parecido al que habían propuesto la DAC en 1935 que al sugerido por Bullrich para esa región, ya que seguía en un primer tramo el río Uruguay y luego el alto Paraná: en principio debía unir la base de El Palomar con Yeruá (Entre Ríos), Monte Caseros (dando acceso a los ferrocarriles del Noreste), Posadas e Iguazú; poco después se agregaría Asunción de Paraguay como destino último y luego una ruta complementaria a Clorinda (Formosa). Tras vuelos experimentales en 1943, el servicio regular se estableció finalmente el 6 de enero de 1944, transportando poco más de 1.700 pasajeros en su primer año. Un año más tarde, argumentando la "necesidad colectiva" derivada de la escasez de combustible y repuestos ocasionado por la Segunda Guerra Mundial, la recién creada Secretaría de Aeronáutica dispuso que algunos de los aviones de LASO y LANE brindaran un servicio de temporada entre El Palomar y el balneario de Mar del Plata ${ }^{16}$. En sus cuatro meses de existencia, la línea transportó 3500 pasajeros. Casi simultáneamente, a comienzos de 1945, todas estas las líneas fueron reorganizadas bajo una única empresa: las Líneas Aéreas del Estado (LADE).

Los textos de creación de LASO y LANE dejaban en claro las concepciones que circulaban en el ámbito militar en torno a la aeronavegación comercial. Por un lado, los militares adherían sin dudas -como Bullrichal principio que afirmaba que las rutas de cabotaje debían ser nacionales, esto es pertenecer al Estado, que debía planificar de manera integral el sistema, regular y controlar de modo centralizado, concesionando las rutas a empresarios privados si resultaba conveniente para los intereses nacionales. Además de pieza clave en la defensa nacional, para los militares el transporte aéreo era un servicio público: su nacionalización resultaba entonces una precondición para el cumplimiento de esa función, al permitir

15 Como dijimos, Aeroposta recibía un subsidio estatal por kilómetro volado (no por pasajero/kilómetro o tonelada/ kilómetro); la ruta de la cordillerana austral, que servía localidades con muy baja población -varias con menos de 1.000 habitantes- era muy extensa y por lo tanto aportaba un subsidio substancioso. Tras la incorporación de la nueva ruta Aeroposta tuvo varios ejercicios con superávit (Piglia 2016: 42-43).

16 Aeroposta fue autorizada a brindar un servicio similar (desde su aeródromo en Morón a Mar del Plata), compitiendo con LADE en esa misma temporada. 
al Estado "la coordinación entre las diversas formas de transporte [...] el establecimiento de rutas de fomento y el cumplimiento de la vasta obra de cultura y progreso." (Decreto 9.255 1943) C Como a Bullrich, a los aviadores del Ejército tampoco los conformaba la política de subsidios con la que se manejaba el transporte aerocomercial. Para ellos, también la solución de preferencia era un mercado de concurrencia regulada basado en aerolíneas mixtas. Sin embargo, proponían una mayor participación estatal: las líneas rentables podían ser privadas o mixtas, mientras las deficitarias -las muy necesarias rutas de fomento- debían ser administradas directamente por el Estado (Parodi 1939: 3). En los considerandos del decreto de creación de las LANE se afirmaba que

[...] las líneas aéreas generalmente deficitarias deben ser administradas ajustadamente en miras a obtener el equilibrio entre los costos y los ingresos, o por lo menos a reducir las pérdidas al mínimo, propósito bien difícil de cumplir con el régimen de subvenciones hasta ahora existente (decreto 9.255 1943).

Como dijimos, para los militares, la aviación comercial era una parte importante del poder aéreo. En la Argentina que rechazaba ideas de conquista

[...] una pequeña fuerza aérea, más que nada escuela de comandos y especializaciones y un intenso desarrollo de las líneas aerocomerciales, resolvería para el país el problema de su seguridad ante el "peligro aéreo" en una forma económica eficaz y concordante con su política internacional (Fuerza Aérea Argentina1945: 26).

La aviación comercial permitía mantener entrenados y con gran conocimiento del territorio a un buen número de pilotos, disponer de aeronaves e infraestructuras que se podían usar para fines de defensa nacional llegado ese caso y podría alimentar el desarrollo de la producción nacional de aviones (Fuerza Aérea Argentina 1945: 26). Este carácter estratégico, reforzaba, a su juicio, la necesidad de que el Estado (y en particular las Fuerzas Armadas) se ocupasen de su planificación, reglamentación y control: "este comando considera -afirmaba el proyecto de LASO- que el establecimiento de líneas aéreas sobre nuestro territorio, deben ser nacionales, coordinadas integralmente por la Aviación del Ejército ${ }^{17}$, en lo que a aviación continental se refiera" (el subrayado es mío) (Parodi 1939: 2). En la concepción militar el poder aéreo era indivisible: todos sus

17 La aviación como arma separada, la Fuerza Aérea Argentina, se creó recién a comienzos de 1945. 
componentes debían confluir "conjugadamente" y, por lo tanto, estar en manos militares (Güiraldes y Rawson Bustamante 1949: 29).

\section{LA DEFINICIÓN DE UNA POLÍTICA AEROCOMERCIAL INTEGRAL}

En 1943 un golpe militar, encabezado por un grupo de oficiales nacionalistas y dentro del cual el Coronel Juan D. Perón fue ganando preeminencia, derrocó al desprestigiado gobierno conservador ${ }^{18}$. La Argentina siguió con la política de neutralidad respecto a la Guerra que habían iniciado los conservadores y que los propios británicos propiciaban, preocupados por la creciente influencia norteamericana en América. La Guerra había estimulado las exportaciones de alimentos e impulsando la industrialización, y a los militares les preocupaban los efectos que las perturbaciones de posguerra pudieran tener sobre el nivel de empleo y sobre todo, con la experiencia de la Gran Depresión detrás y el temor al comunismo, sus efectos políticos. A la vez, tras la entrada de Estados Unidos en el conflicto mundial, la resistencia de la Argentina a alinearse con la potencia del norte había resultado en represalias económicas y en desequilibrios regionales, ya que las fuerzas armadas brasileras recibieron apoyo norteamericano para reequiparse. En ese marco, el gobierno de facto (1943-1946) y luego el gobierno constitucional de Perón (1946-1955) que lo sucedió, profundizaron el sendero de nacionalismo económico y búsqueda de autonomía diplomática que la Argentina venía recorriendo desde el comienzo de la contienda, procurando alcanzar la hegemonía regional a la que los dirigentes argentinos todavía confiaban en poder aspirar.

En ese marco, la cuestión de la aviación fue abordada por primera vez de modo integral. En enero de 1945 el Comando de Aviación del Ejército, se convirtió en un arma separada, la Fuerza Aérea. Algo más tarde, a finales de abril de 1945, un nuevo decreto fijó la política aérea nacional. Las aspiraciones quedaban claras en los considerandos del decreto: proteger los intereses de la nación en su espacio aéreo, estimulando el desarrollo de "las actividades económicas, sociales y políticas del país", contribuir a la defensa

18 Los gobiernos conservadores de la década del treinta se caracterizaron por la práctica sistemática del fraude electoral. Esos gobiernos dependieron en buena medida de los efectos legitimadores de la obra pública. En 1938 Justo fue sucedido por el presidente Roberto M. Ortiz, que tuvo que retirarse prematuramente de su cargo por razones de salud, quedando a cargo Ramón S. Castillo. Con menos habilidad política que Justo, Castillo, cuyo gobierno sufrió las tensiones económicas y políticas impuestas por el comienzo de la Segunda Guerra, se volvió crecientemente impopular. 
nacional y reforzar la posición continental de la Argentina propendiendo "al desarrollo intensivo de las comunicaciones con las naciones americanas y el resto de los países del mundo, en miras de hacer efectivos los propósitos de solidaridad continental que caracteriza la política internacional de la República Argentina” (Decreto 9.358 1945: considerandos)

La nueva norma nacionalizaba todo el tráfico aéreo interno y ponía la aviación civil, deportiva y comercial bajo el mando unificado del órgano máximo de la recién creada Secretaría de Aeronáutica, luego Ministerio. Se nacionalizó toda la infraestructura de tierra (incluyendo las comunicaciones y la meteorología) y se reservó el transporte de cabotaje para empresas estatales o mixtas. La Secretaría de Aeronáutica quedó autorizada a constituir esas sociedades mixtas, "cuidando especialmente de establecer en sus estatutos la condición de argentinos nativos de sus socios, el carácter nominativo de las acciones y el domicilio dentro del país de las sedes sociales" (Decreto 9.358 1945: art. 5)

Con un diseño que debía mucho a los planteos de Bullrich (aunque sin mencionarlo), en 1946 se crearon tres empresas mixtas, a las que se les asignaron monopolios regionales: ZONDA (Zonas Oeste y Norte) que tomó las rutas que antes volaba Panagra; ALFA (Sociedad Mixta de Aviación del Litoral Fluvial Argentino) en el Litoral, sobre la base de la Corporación Sudamericana de Servicios, que absorbió también las rutas de LANE; y la Sociedad Mixta Aeroposta Argentina, que absorbió a Aeroposta Argentina S.A. (Patagonia) y obtuvo las rutas de LASO y de la línea a Mar del Plata de LADE, y que equivalía las rutas sur y cordillerana del diseño de Bullrich (véase mapas 2 y 3 ). Habiendo perdido todas sus rutas, a LADE se le encomendó la apertura y operación de rutas de fomento. En 1947 se le asignó un itinerario nuevo, denominado "ruta A", entre El Palomar, Azul, Bahía Blanca, Santa Rosa, San Luis y Córdoba (Fuerza Aérea Argentina 1990: 62).

El Estado participaba con un 20\% del capital de las empresas mixtas de cabotaje, aunque asumía la responsabilidad de cubrir los déficits operativos y de garantizar al capital privado un rendimiento mínimo del $5 \%$. Las compañías eran administradas por un directorio presidido por representantes del Estado (Presidente y Vicepresidente) e integrado por cuatro directores, con sus suplentes, designados por los accionistas privados.

Respecto de líneas aéreas internacionales, el decreto de abril también seguía los lineamientos planteados en el informe de Bullrich: las líneas de transporte internacionales podrían operar libremente mientras ingresaran por un aeropuerto de frontera, sobre territorio argentino siguieran las 
rutas definidas por el Estado y, fundamentalmente, sus países de origen otorgaran similares beneficios a las líneas aéreas argentinas. Al momento del decreto, Argentina no tenía a la sazón una aerolínea que realizara vuelos internacionales: mientras diplomáticamente se comenzó a defender con ahínco (y con éxito) las relaciones bilaterales recíprocas como forma de organización de la aviación comercial internacional y, por lo tanto, el derecho de los países periféricos a una parte de ese tráfico (Piglia 2016), a fines de 1945 se creó la primera línea aérea internacional "de bandera": la Flota Aérea Mercante Argentina (FAMA). FAMA tenía un estatuto diferente de las demás compañías mixtas, tenía un capital mucho mayor (alrededor de diez veces más que el de ZONDA o Aeroposta) y la participación del Estado era mayor (un tercio del capital). Comenzó a operar en 1946, tras la firma de un acuerdo bilateral de reciprocidad con Gran Bretaña.

El resto de las compañías mixtas se puso en marcha entre fines de 1946 y 1947. En el nuevo esquema se adquirieron nuevos aviones, aunque menos que los que se planeaba adquirir y más anticuados. A la lentitud del Estado en integrar el capital comprometido, crucial para la renovación de las flotas se sumaban las dificultades de la Argentina para adquirir máquinas en la zona del dólar, producto del boicot norteamericano -consecuencia de la neutralidad argentina en la Guerra- y de la inconvertibilidad de la libra, moneda en la que Argentina había acumulado un saldo acreedor con Gran Bretaña. La compra de aeronaves nuevas tenía además, importantes demoras y requería, como en el caso de los Douglas DC-6, inversiones para dotar los aeropuertos de pistas firmes de la que la mayoría carecía ${ }^{19}$. Sin embargo, las empresas tuvieron una expansión de sus servicios: se sumaron rutas nuevas en el Litoral y en las otras dos zonas, la de Aeroposta y la de ZONDA, las líneas principales (a Esquel, a la cordillera sur, a la costa austral, a Mendoza, a Salta), multiplicaron sus escalas intermedias (véase mapa 3). Con el crecimiento de la conectividad aérea y de la frecuencia de los vuelos (gracias a la ampliación de la flota) creció el número de pasajeros que pasaron de un poco más de 67.000 en 1943 a casi 109.000 en 1947, esta última cifra incluye los vuelos de FAMA (Aerolíneas Argentinas 1959: 7, Memoria de la DAC 1943: 1-2).

Desde el punto de vista de su rendimiento, las nuevas empresas tuvieron resultados decepcionantes aún cuando, como declaraba el último balance de Aeroposta Sociedad Mixta "la aviación comercial, en su estado presente, no puede considerarse todavía como una industria lucrativa o una empresa normal, capaz de cubrir sus gastos con sus propios ingresos y, menos aún,

19 El aeropuerto Internacional de Ezeiza se inauguró en 1949 y el Aeroparque de Buenos Aires en 1947. 
de proporcionar utilidades" (Aeroposta 1949: 2). Acumularon cuantiosos déficits, que en parte se achacaban a la demora del Estado en integrar los capitales comprometidos y a la lentitud con la que se mejoraba la infraestructura de tierra: el rudimentario estado de muchos aeródromos aumentaba, por ejemplo, los costos de mantenimiento de los aviones (Aeroposta 1949: 18) ${ }^{20}$. Aeroposta resultó la más eficiente y rentable de las empresas mixtas y sus prácticas fueron tomadas como modelo para las otras compañías (y más tarde para Aerolíneas Argentinas Aerolíneas 1950:14). Así sucedió, por ejemplo, con los controles de salud obligatorios y estrictos a los pilotos introducidos por la Aeroposta privada y que fueron norma en las empresas mixtas (entrevista a C.G 2014). Sin embargo, aún siendo la más eficiente, Aeroposta requirió del Estado muchos más recursos al año que en los tiempos de los subsidios por kilómetro (esto además del capital integrado por el Estado): en 1947 el aporte fue un 316\% mayor que en 1945.

Esta experiencia de empresas mixtas duró sin embargo muy poco. Para 1949 las cuatro empresas mixtas fueron nacionalizadas y luego reunidas en una única línea aérea monopólica: en 1950 nacía Aerolíneas Argentinas. El argumento central fue económico: si el Estado tenía que contribuir en tal grado al sostenimiento de las mixtas, más valía que fueran directamente de su propiedad; por otro lado, aspiraban a que el paso del esquema de "monopolio por regiones" (propuesto en el informe de Bullrich y puesto en marcha por el decreto de 1945) al de monopolio ffnacional, permitiera generar economías de escala y reducir el déficit operativo Aerolíneas 1950: 1-11). El control "indiviso" del "poder aéreo" por parte de los militares tuvo una vida aún más breve: en 1948 Perón decidió el traspaso de la aviación comercial a manos civiles, quedando a cargo de la Secretaría de Transportes (luego Ministerio).

20 Así, FAMA, que tenía teóricamente un capital de algo más de \$ 100.000.000, acumuló entre 1946 y 1949 un déficit de \$ 87.200.000; Aeroposta, con un capital de $\$ 10.000 .000$, un déficit de $\$ 14.260 .000$ y ZONDA con un capital similar, un déficit aún mayor (\$23.780.000) (Aerolíneas 1950: 11). 
Mapa 3: Rutas de las compañías mixtas, 1948

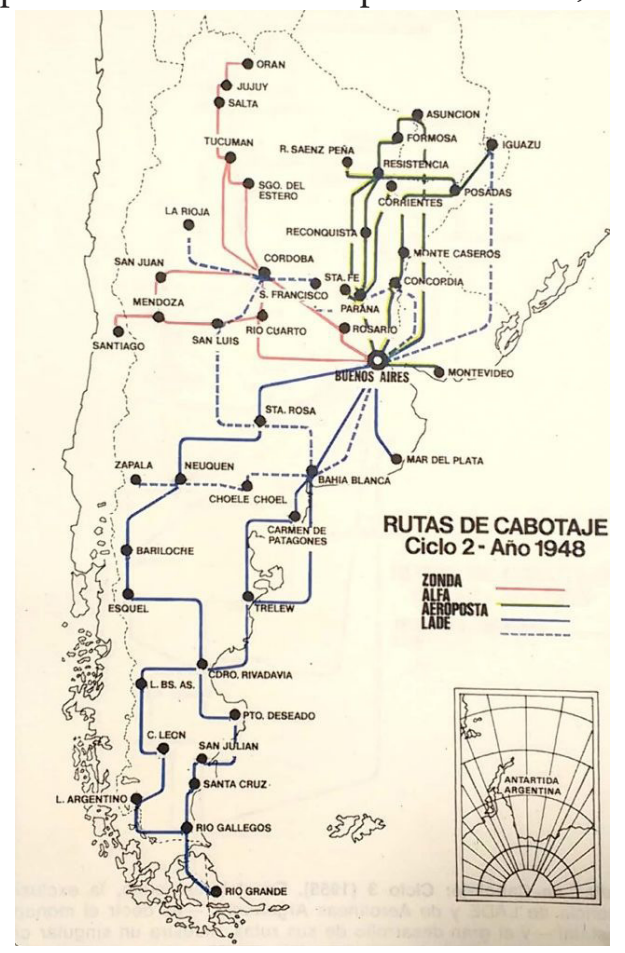

Fuente: Güiraldes (1979: 119).

\section{DEL MONOPOLIO A LA CONCURRENCIA REGULADA}

Entre 1950 y 1956 Aerolíneas Argentinas explotó de modo casi monopólico ${ }^{21}$ el cabotaje y fue la línea aérea de bandera de la Argentina. Sus rutas se multiplicaron y para 1955 todas las capitales de provincia tenían servicio aéreo y estaban conectadas con Buenos Aires, la capital del país. El esquema de rutas, aunque mucho más denso y rico en escalas intermedias que los diseñados en los años treinta, recuerda las propuestas de la DAC: Mendoza, Córdoba y Tucumán operaban como nodos importantes y el sistema permitía una gran conectividad intra e interregiones (sur/norte, costa/andes, noroeste/noreste) a partir de esos nodos.

En 1955 un golpe de Estado desalojó a Perón del poder. En el clima de cuestionamientos generales a todo lo implementado por el gobierno depuesto, los militares que habían encabezado el golpe discutieron la suerte de Aerolíneas y hubo propuestas para desmantelarla. A pesar de las amenazas, finalmente Aerolíneas no fue disuelta, pero sus privilegios fueron

21 Recordemos que LADE volaba algunas rutas de fomento. 
recortados. De algún modo, la política aérea volvió a acercarse a las líneas planteadas por la normativa de 1945: una serie de decretos del gobierno de facto (1955-1958) en 1956 y 1957 autorizaron la concesión de una parte del mercado aéreo (tanto de vuelos nacionales como internacionales) a aerolíneas privadas (Decretos-Ley 12.5071956 y 1.256 1957). Varios años más tarde, el gobierno constitucional del presidente Arturo Illia (19631966) defendiendo esa normativa, sostendría que la habilitación de la actividad aerocomercial privada nacional había sido, y continuaba siendo, una forma de aumentar la cantidad de servicios aéreos sin acrecentar el esfuerzo presupuestario del Estado y protegiendo "a la sociedad de las eventuales consecuencias desfavorables de esa política [de explotación privada], mediante la existencia de una Empresa del Estado y adecuados reglamentos para regular la competencia" (Poder Ejecutivo Nacional 1964: capítulo 13, s/n).

Los decretos de 1956 y 1957 reservaron la prestación de servicios internacionales con bandera argentina para la empresa estatal y mantuvieron en manos del Estado aeropuertos, radiocomunicaciones y meteorología, a la par que establecían un sistema de concurrencia regulada para el mercado de cabotaje. Las empresas privadas debían pertenecer a capitales nacionales; en su conjunto, nunca podrían superar el 50\% del mercado y las tarifas serían las mismas para todos. La competencia -sostenían las autoridades- debía realizarse solamente por la calidad del servicio (Poder Ejecutivo Nacional 1964: capítulo 13, s/n). El decreto preveía que el Estado contribuiría a cubrir los "déficits de una sana explotación" de las empresas privadas de cabotaje, sobre la base de primas kilométricas (esta contribución no podía aplicarse a la compra de aeronaves o repuestos). Como en ninguno de los ejercicios financieros el monto asignado por el Estado resultó suficiente para cubrir los cuantiosos déficits de estas empresas, decretos posteriores establecieron un prorrateo sobre la base de su eficiencia, medida en pasajeros-kilómetro transportados.

Un buen número de nuevas aerolíneas apareció en los años siguientes. La mayoría no competía directamente con Aerolíneas, sino que explotaba rutas regionales o zonales que complementaban y alimentaban las rutas principales de la empresa estatal: ese era el caso de TABA en la provincia de Buenos Aires y de Aerochacho, una compañía mixta (con capitales del gobierno provincial) que explotaba rutas en el Noreste. A otras compañías se les concedió una cuota del mercado, de entre el 20 y el 30\% de algunas rutas centrales: Austral volaba a los destinos más rentables de la Patagonia, mientras ALA tenía rutas en el Litoral con base en Rosario. 
La acumulación de déficits de explotación e inversión de las empresas privadas llevaron a la temprana desaparición de varias de ellas, y a la fusión de ALA y Austral en Austral Líneas Aéreas en 1971.

\section{CONCLUSIONES}

Si en los ańos veinte había sido un experimento y una novedad, para mediados de los años treinta la aviación emergía como una forma de transporte con enormes potencialidades para el progreso nacional. El gobierno de Justo se caracterizó por, en buena medida, actualizó una forma de pensar los problemas nacionales en clave territorial, contemplando a la vastedad y la desconexión como causas del atraso, y buscó en la obra pública su solución (Ballent y Gorelik 2002). Su política se caracterizó por un nacionalismo moderado, que fortaleció la capacidad del estado nacional de planificar hasta cierto punto el progreso, frente a las faltas de coordinación producto de la libre competencia o de la multiplicidad de jurisdicciones, o frente a la voracidad de los intereses extranjeros. La centralización de la planificación y la construcción de la red nacional de caminos y el ordenamiento del mercado de las naftas sobre la base de un replanteo del rol de YPF formó parte de esa lógica, que en 1937 puso en foco al transporte aerocomercial.

A la vez, en esos años de creciente inestabilidad internacional y preparativos para la guerra, los militares estaban cada vez más convencidos del papel vital de la aviación (del poder aéreo) en la defensa nacional, y, dentro de ella de la aviación comercial. Justo, ingeniero y militar, derivaba su interés probablemente de ambas fuentes. El informe de Bullrich, persona de su confianza, sintetizaba y sistematizaba estas preocupaciones y tendencias, proponiendo un esquema que buscaba proteger los intereses nacionales, nacionalizando el cabotaje, poniendo en manos del Estado la coordinación, planificación y control y planteando un sistema de rutas y compañías que debía estar subordinado a los intereses económicos, políticos y militares de la nación. Sin embargo, como vimos, ponía a la defensa nacional en el marco de un interés estatal más amplio, lo que implicaba el control civil de la aviación comercial y la atención primordial a otras cuestiones (el confort de los pasajeros, la idoneidad de todo el personal, la puntualidad y velocidad de los vuelos). Desde su perspectiva, concentrarse en fomentar el desarrollo de la aviación comercial en los términos que esta requería (velocidad, comodidad, confiabilidad, seguridad) -sin sacrificarlos en aras de su sometimiento a lógicas militares- traccionaría el desarrollo global de la aviación (formación de pilotos, construcción de infraestructura, desarrollo de rutas, producción local de aviones, etc.). En el tiempo transcurrido entre que Bullrich comenzó su investigación y la entrega final de su informe, 
el panorama político sufrió transformaciones importantes. El cambio de gobierno (Ortiz había asumido el 20 de febrero de 1938) y el deterioro de la situación europea, alteraron las posibilidades, las prioridades y los planes para la Argentina, muy contrastantes con los proyectos que Justo podía haber tenido en 1937, y eso frustró sus posibilidades de que por entonces cristalizara una política aérea integral.

Como vimos, en sintonía parcial con estas ideas de Bullrich, en los ámbitos castrenses venían madurando también concepciones y proyectos sobre la aviación comercial que giraban en torno a las ideas del poder aéreo y de su contribución a la defensa nacional. Para los militares la nacionalización del cabotaje era el punto de partida necesario y el Estado debía tener un rol activo organizando, regulando, pero también prestando de modo directo el servicio y/o participando de empresas mixtas -en las rutas rentables. A diferencia de Bullrich, lógicamente para los militares el objetivo de prepararse para posibles escenarios de defensa era central, como también lo era mantener toda la aviación bajo un mando centralizado y militar.

De alguna manera, el decreto de abril de 1945 condensó estas dos líneas. Del proyecto civil tomaba la preferencia por las empresas mixtas, la concurrencia regulada y el monopolio por regiones para la organización del cabotaje y el bilateralismo en materia de vuelos internacionales; del militar, el mando indiviso y la fuerte regulación estatal; de ambos, la nacionalización del cabotaje y los servicios e infraestructura de tierra.

Con tensiones y algunas contramarchas las grandes líneas de esta suerte de consenso regirían la política aérea argentina de las décadas siguientes, a través de gobiernos civiles y militares, de signos ideológicos contrastantes. Una de estas grandes líneas es, sin duda, la cuestión de la soberanía completa y exclusiva sobre el espacio aéreo, que se interpretó de modo amplio. Esta interpretación aseguró la continuidad de la fuerte regulación estatal y de la participación directa del Estado en el sostenimiento material de la actividad (prestación directa con Aerolíneas y LADE, subsidios a las empresas privadas, empresa mixta provincial, en el caso de Aerochaco). Implicó además la persistente exclusión de las empresas extranjeras del mercado de cabotaje: cuando se autorizó nuevamente la actividad de aerolíneas privadas en 1956, se exigió que estas fueran de capitales nacionales. Por otro lado, en materia de aviación internacional, la asimilación entre la línea de bandera, FAMA inicialmente, luego Aerolíneas Argentinas, y la representación de la patria, llevó a que muchas rutas internacionales -en las que la cuestión no era el servicio público y la conectividad, puesto que se competía con otras empresas extranjeras que prestaban el servicio-, 
se mantuvieran funcionando a pasar de que resultaban fuertemente deficitarias, por razones de índole geopolítica y simbólica. El tráfico aéreo generado por la Argentina fue concebido como una de las riquezas de la nación que debía ser defendida y la Argentina se mantuvo durante décadas firme en la defensa de la reciprocidad y el bilateralismo como regla para los servicios internacionales.

Otra de estas líneas que había consagrado el decreto de 1945 era el principio, que pocos discutían abiertamente hasta los años setenta, de que el transporte aéreo por sus características (escasa rentabilidad, altos costos) y su importancia estratégica, en el contexto además del reducido tamaño del mercado local, no podía quedar librado a las fuerzas de la libre competencia. El mercado aerocomercial de cabotaje argentino fue desde 1945 un mercado regulado: tras el cuasi monopolio de Aerolíneas entre 1950 y 1956, se volvió a un sistema de concurrencia regulada, con una empresa principal -Aerolíneas- y otras que explotaban de modo complementario y organizado una cuota menor del tráfico. A partir de 1956, la organización de las nuevas líneas aéreas tendió a seguir el criterio regional sugerido por la DAC y Bullrich e impuesto por el decreto de 1945 , aunque complementado por otra división entre líneas "de fomento" (asignadas a LADE) y líneas rentables o comerciales: las nuevas aerolíneas privadas y la mixta Aerochaco, recibieron rutas circunscriptas a una región o a una zona dentro de una región.

Quizás en este estrecho vínculo entre transporte aéreo y soberanía y en esta mirada sobre el transporte aerocomercial como servicio público y como factor central para el desarrollo, pueda encontrarse una clave para explicar la perduración de Aerolíneas Argentinas (privatizada en 1991 y estatizada nuevamente, con gran aprobación popular, en 2008) y su lugar como atributo de la identidad nacional. 


\section{REFERENCIAS}

Adey, P. (2010). Aerial Life: Spaces, Mobilities, Affects. West Sussex: WileyBlackwell.

Aerolíneas Argentinas (1950). Aerolíneas Argentinas. Nacionalización y Unificación. 1949-4 de mayo-1950. Buenos Aires: Aerolíneas Argentinas.

Aerolíneas Argentinas.

Aeroposta (1939a). Un Anhelo y una Necesidad de Pueblos de la Patagonia Austral. Revista Aeroposta, 3.

(1939b). El transporte Aéreo y la Economía en la Argentina. Subvenciones y Primas del Estado al Transporte Aéreo Según La Experiencia de las Compañías. Revista Aeroposta, 4.

Aeroposta. . (1949). Memoria y Balance de Aeroposta. Buenos Aires:

Ballent, A. y Gorelik, A. (2002). País Urbano o País Rural: La Modernización Territorial y su Crisis. En Cataruzza, A. (Dir.), Nueva Historia Argentina. Buenos Aires: Sudamericana.

Ballent, A. (2002). El Peronismo y sus Escenarios. La Operación Territorial de Ezeiza (1944-1955). Entrepasados, 22, 7-26.

Bullrich, E. J. (1938). Régimen y Organización de la Aeronáutica Civil. Buenos Aires: Imprenta del Congreso de la Nación Argentina.

Dirección de Aeronáutica Civil (DAC) (1935). Lineas Aéreas Nacionales en Actividad y Proyectadas. Buenos Aires: Dirección de Aeronáutica Civil.

Fuerza Aérea Argentina (1945). Antecedentes de las LADE. Archivo División de Estudios Históricos de la Fuerza Aérea, Buenos Aires, Argentina.

(1990). Lineas Aéreas del Estado, 1940-1990, $50^{\circ}$ Aniversario. Buenos Aires: Fuerza Aérea Argentina.

Gadano, N. (2006). Historia del Petróleo en la Argentina. 1907-1955: Desde los Inicios hasta la Caída de Perón. Buenos Aires: Edhasa. 
Güiraldes, J. J. (1979): El Poder Aéreo de los Argentinos. Buenos Aires: Círculo de la Fuerza Aérea, Dirección de Publicaciones.

Güiraldes, J. J. y Rawson Bustamante, J. (1949). El Poder Aéreo. Sus Factores. Su Indivisibilidad. Revista Nacional de Aeronáutica. 2 (3).

Martínez, S. R. (2013). Aquellos Precursores. Buenos Aires: Dunken.

Ministerio de Guerra (1943). Complemento de la Memoria de la Dirección General de Aeronáutica Civil. Buenos Aires: Ministerio de Guerra.

Parodi, A. (1939). Proyecto de Linea Aeropostal Militar. Comando de Aviación del Ejército, Archivo División de Estudios Históricos de la Fuerza Aérea, Buenos Aires, Argentina.

Piglia, M. (2016). Aviación Comercial y Fomento del Progreso: La Aeroposta Argentina, el Desarrollo de la Patagonia y los Orígenes de la Política Aerocomercial (1927-1949). En Rougier, M. y Odisio, J. (Eds.), Estudios sobre Planificación y Desarrollo. Carapachay: Lenguaje Claro Editora.

. (2017). Aeromovilidad. En Giucci, G. y Zunino Singh, D. (Eds.), Términos Clave para los Estudios de Movilidad en América Latina. Buenos Aires: Biblos.

- (en prensa). Aeromovilidad, Tecnología y Poder. El Caso de la Modernización de la Flota de Aerolíneas Argentinas. Revista de Historia de la Economía y la Empresa.

Poder Ejecutivo Nacional (1964). Contestación al Pedido de Informes de la Honorable Cámara de Diputados de la Nación. Buenos Aires: Poder Ejecutivo Nacional.

Potenze, P. (1987). Aviación Comercial Argentina, 1945-1980. Buenos Aires: El Cronista Comercial.

Urry J. y Sheller, M. (2006). The New Mobilities Paradigm. Environment and Planning, 38, 207-226.

Leyes, decretos y archivos

B.O.R.A. (Boletín Oficial de la República Argentina) (1935) 7 de mayo. 
Boletin de Informaciones Petroleras (abril de 1945).

Datos Estadisticos. Octubre de 1944-septiembre de 1945 (1945). Buenos Aires: Archivo Histórico del Ministerio de Economía.

Decreto 9.255, 1943, Buenos Aires, Argentina.

Decreto 9.358, 1945, Buenos Aires, Argentina.

Decreto-Ley 12.507, 1956, Buenos Aires, Argentina.

Decreto-Ley 1.256, 1957, Buenos Aires, Argentina.

HCDN (Diario de Sesiones de la Honorable Cámara de Diputados de la Nación) (1934), sesión del 29 y 30 de julio.

Recibido: 23-05-2018

Aceptación de la versión final: 25-06-2018 